\title{
Giant ventricular myxoma obstructing right ventricular outflow tract
}

\author{
Mixoma ventricular direito gigante obstruindo via de saída do ventrículo direito
}

\author{
Trushar P. Gajjar ${ }^{1}$, Gaurang B. Shah ${ }^{1}$, Neelam B. Desai ${ }^{2}$
}

DOI: $10.5935 / 1678-9741.20110060$

RBCCV 44205-1336

\section{Abstract}

Intracardiac myxoma is predominantly located in the left atrium but their location in the right ventricle is quite unusual. We present a case in which successful excision of the tumor was done through bicameral approach.

Descriptors: Myxoma. Echocardiography. Ventricular septum.

\section{INTRODUCTION}

Intracardiac myxoma is the most common tumor of the heart, with an estimated incidence of 0.5 cases per million people per year [1]. Approximately $75 \%$ of these tumors arise from the left atrium and $18 \%$ from the right atrium. Few others originate from atypical sites such as left or right ventricle and valves. Depending on the size and location of the tumor presenting symptoms may vary. Very few cases of isolated right ventricular myxomas have been reported in the literature. We are reporting a case of young female
1. Sri Sathya Sai Institute of Higher Medical Sciences, Consultant Cardiothoracic Surgeon.

2. Sri Sathya Sai Institute of Higher Medical Sciences, Senior Consultant, Cardiothoracic Surgery Department.

This work was performed at Department of Cardiothoracic and Vascular Surgery, Sri Sathya Sai Institute of Higher Medical Sciences, Prasanthigram, District Anantapur Andhra Pradesh, India.

\section{Resumo}

Mixoma intracardíaco localiza-se predominantemente no átrio esquerdo, e sua localização no ventrículo direito é bastante incomum. Apresentamos um caso no qual excisão bem sucedida do tumor foi feita por meio de abordagem bicameral.

Descritores: Mixoma. Ecocardiografia. Septo interventricular.

with a huge right ventricular myxoma obstructing the right ventricular outflow tract.

\section{CASEREPORT}

A 42 year old female patient presented with difficulty in breathing on moderate exertion, syncope, palpitation and chest pain. On examination there was a grade $3 / 6$ ejection systolic murmur. There was no evidence of the Carney's complex or family history of the cardiac mass. Chest X-ray revealed cardiothoracic ratio of $60 \%$ with no evidence of
Correspondence address

Trushar P. Gajjar

C-7, Residential Block - SSSIHMS Campus - Prasanthigram-515134

- District Anantapur, Andhra Pradesh, India

E-mail: trushargajjar@gmail.com 
the pulmonary metastasis. Electrocardiogram showed sinus rhythm with heart rate of 70 per minute. Transthoracic and transesophageal echocardiogram showed dilated right atrium and ventricle with a $9 \mathrm{~cm} \times 6 \mathrm{~cm} \times 5 \mathrm{~cm}$ sized homogenous mass, attached on the right ventricular side of interventricular septum without calcification or hyperlucency (Figure 1A).

The mass was prolapsing into the right ventricular out flow tract (RVOT) and pulmonary artery (PA) (Figure 1B) producing the RVOT gradient of $75 \mathrm{mmHg}$. The tricuspid annulus was dilated which was measuring about $42 \mathrm{~mm}$ with severe tricuspid regurgitation and severe right ventricular dysfunction. The contrast enhanced computed tomogram was negative for the pulmonary and hepatic metastasis. A few days after the diagnosis, patient was taken up for surgery. The approach was through a conventional median sternotomy; the pericardium was opened and stayed.
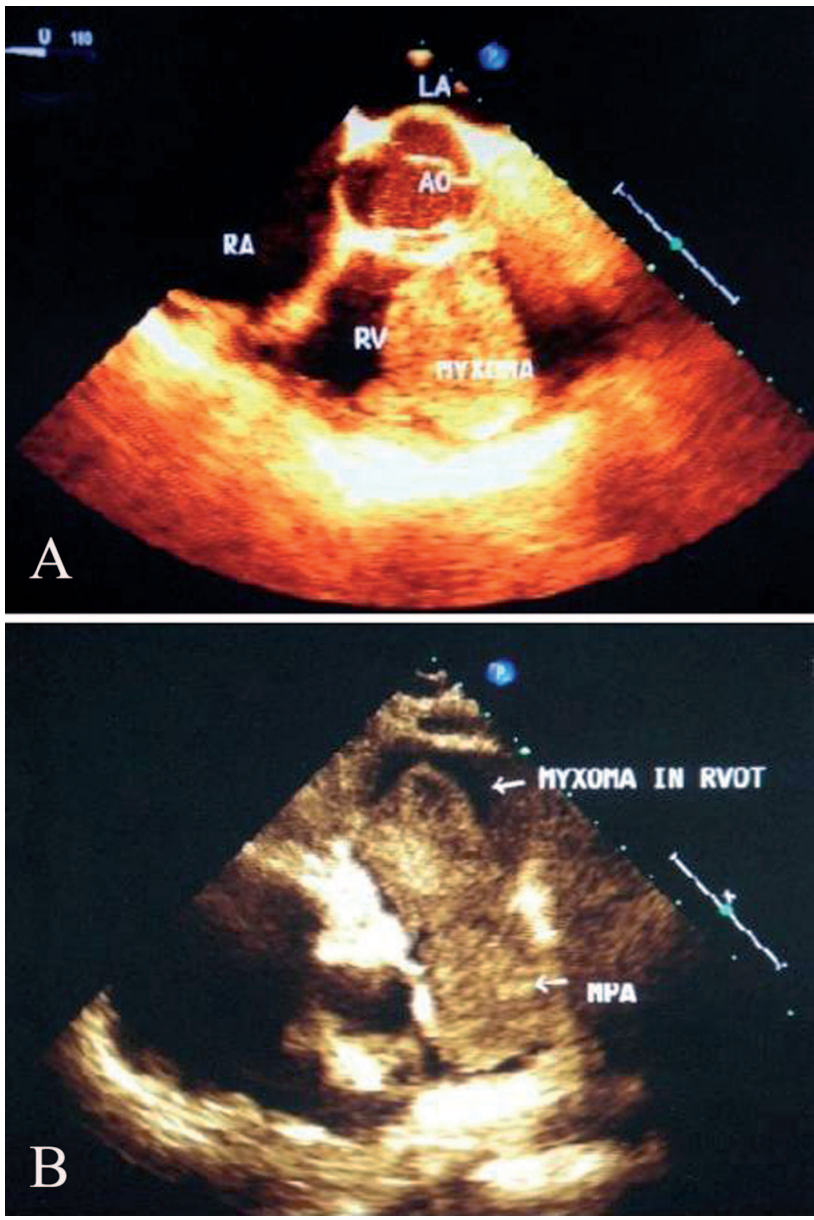

Fig. 1 - Transesophageal echocardiogram showing: A - right ventricular myxoma with its attachment to the septum; $B$ - right ventricular myxoma prolapsing into the main pulmonary artery causing right ventricular outflow tract obstruction. LA $=$ Left Atrium; $A o=$ Aorta $; R A=$ Right Atrium $R V=$ Right Ventricle, MPA = Main Pulmonary Artery
Cardiopulmonary bypass was established after the aortic and bicaval cannulation. Under moderate hypothermia the aorta was cross clamped and a cold blood antegrade root cardioplegia was given. Both vena cava were looped after cross clamping the aorta to prevent embolization of tumor. The main pulmonary artery (MPA) and the right atrium (RA) were opened. A $9 \mathrm{~cm}$ x $6 \mathrm{~cm}$ x $5 \mathrm{~cm}$ sized, grayish brown, well encapsulated mass without any frond like projections was attached to the mid muscular part of the interventricular septum with narrow well defined stalk. The surrounding muscles were hypertrophied with some amount of fibrosis. The mass was obstructing the right ventricle and its outflow tract and was prolapsing into the main pulmonary artery (Figure 2).

The tumor was excised from the MPA and the RA along with its stalk and the surrounding portion of the interventricular septum without creating a ventricular septal defect. After completing the excision, the MPA, branch pulmonary arteries, right ventricle, right atrium and the pericardial cavity were examined for tumor debris and thorough normal saline washes were given. The tricuspid and pulmonary valves were examined and found to be normal. Weaning from the cardiopulmonary bypass was smooth. The macroscopic findings showed a $9 \mathrm{~cm}$ x $6 \mathrm{~cm} \mathrm{x}$ $5 \mathrm{~cm}$ sized grayish brown well encapsulated mass.

On microscopic examination it revealed, the presence of polygonal, spindle shaped and stellate cells with the perivascular cuttings in a myxomatous and hemorrhagic background suggestive of the myxoma. The patient was recovered uneventfully. The echocardiogram done during immediate postoperative period and prior to the discharge showed, no residual myxoma, trivial tricuspid regurgitation and the right ventricular systolic pressure was $25 \mathrm{mmHg}$ with good biventricular function. As patient was operated recently she is awaiting for her first follow up at 3 months.

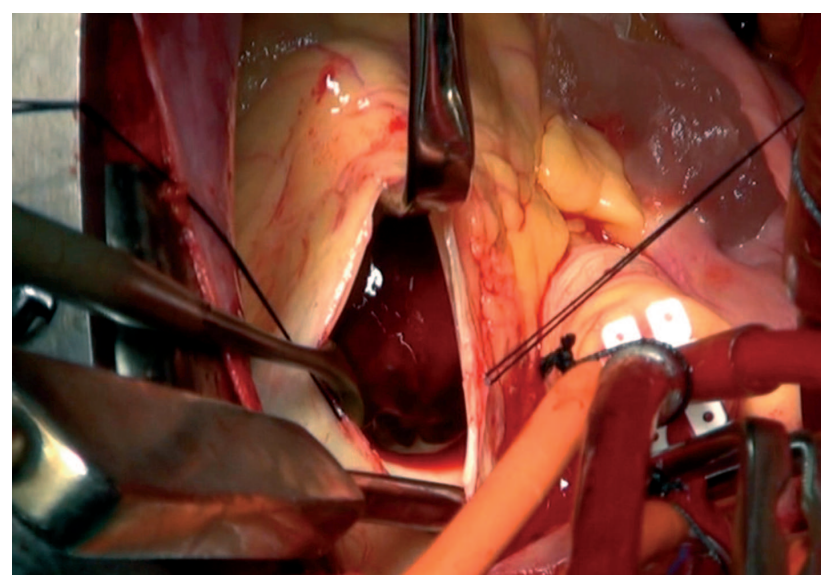

Fig. 2 - Figure showing widely opened main pulmonary artery with right ventricular myxoma prolapsing across the pulmonary valve into it (Picture is taken from the head end of the patient) 


\section{DISCUSSION}

Cardiac myxomas are usually seen in adults, accounting for $25 \%-40 \%$ of all cardiac tumors from birth to adolescence [2]. The majority of myxomas (75\%) are located in the left atrium whereas right ventricular myxomas are only found in $2-4 \%$ of cases [2] and multiple tumors are rarely [3]. A careful review of the literature on cardiac myxomas revealed 36 patients with tumor located in the right ventricle $[4,5]$. Czapek, in 1891, was among the first to provide a pathological description of a right ventricular myxoma [4]. Almost seventy years elapsed before Kishimoto and Sakaibori described another such tumor, which was recognized at postmortem examination, and Michaud and associates reported successful surgical removal of a right ventricular myxoma [5,6].

Myxomas were inserted mainly on the right ventricular wall or interventricular septum; in rare instances they involved the tricuspid valve [2,7]. The tumor was described to be infiltrating the ventricular myocardium in five patients $[2,7]$. In five patients a right ventricular myxoma was associated with other intracardiac myxomas and in one, with extracardiac anomalies [8-10]. From November 1991 till December 2010, total 220 cases of cardiac myxoma underwent surgical removal at our institute and the current case was the first one presented as an isolated right ventricular myxoma.

The right sided cardiac tumors can present with signs and symptoms of congestive cardiac failure or shortness of breath, syncope, fatigue, edema, jugular venous distension, ascites, night sweats and pericardial effusion $[11,12]$. The right ventricular myxoma leads to some of the complications, and these are: vena cava syndrome, pulmonary embolism, right ventricular dysfunction and restrictive cardiomyopathy $[11,12]$.

Electrocardiogram may show partial right bundle branch block due to right ventricular hypertrophy. Plain chest Xray is not diagnostic except for the pulmonary metastasis in cases of malignancy or the metastatic tumor. However the fluoroscopic evaluation may be helpful if the calcification is present in the myxoma [12]. Echocardiography is an excellent way to make a diagnosis by noninvasive means $[12,13]$. Echocardiogram will show a characteristic narrow stalk, tumor mobility and distensibility.

Although broad based, non-mobile myxomas can occur [12]. The myxomas may be homogenous or may have central areas of hyperlucency representing hemorrhage and necrosis [12]. Presence of calcification with echogenic foci can be detected by echocardiogram [12]. Gadoliniumenhanced cardiovascular magnetic resonance imaging is one more noninvasive imaging modalities to differentiate between two different etiologies myxoma and thrombus. This study shows delayed heterogeneous enhancement of the myxoma, whereas it does not show delayed enhancement of thrombus, which helps in conûrming the diagnosis of myxoma [13].

Various surgical approaches have been reported from the right atrium or the right ventricle in the literatures [1012]. The right atrial approach is sufficient in most of the right ventricular myxoma of small to average size. The right ventriculotomy approach may cause postoperative right ventricular dysfunction and it is not advisable. In our case the patient presented in her early 40's with predominant symptoms of syncope and the difficulty in breathing, which is the classical presentation of intracavitary tumor. The family history was negative for the cardiac mass and the Carney's complex was absent on examination. The diagnosis was confirmed by transthoracic and transesophageal echocardiography. The possibility of metastatic tumor was ruled out by 1) absence of signs and symptoms of the primary tumor, 2) absence of the pulmonary and hepatic metastasis on computed tomography scan and 3) absence of the typical locations (valves and extension in inferior vena cava) and appearance of the metastatic tumor on echocardiography.

To prevent the recurrence certain basic and important points to be followed during the intraoperative period and they are, 1) the cardiac manipulation should be minimized to prevent intraoperative embolization until aortic cross clamping, 2) wide resection of the myxoma should be done including adjacent cardiac tissue and septum if required, 3) if the myxoma is removed in piecemeal, all debris should be cleared with careful removal and massive irrigation and suction, 4) an attempt to be made to remove the myxoma intact as far as possible. In our case the surgical approach was bicameral through the right atrium and the pulmonary artery. The bicameral approach helps in easy delivery of the large tumor in total, like in this case. The right atrial approach helps in identifying the stalk and its attachment to the ventricular septum and it also helps to repair the tricuspid valve if required.

The pulmonary artery approach helps in 1) an easy delivery of a large tumor in total without damaging the pulmonary valve, 2) examination of the pulmonary valve and 3) exploration with removal of the tumor debris from the branch pulmonary arteries. In our experience with right ventricular myxomas, complete excision of the tumor was obtained by limiting the parts removed to the endocardium and to the myocardium surrounding the insertion of the pedicle. Full-thickness excision of the right ventricular wall is not justified in our opinion, since there are no reports of recurrence of such neoplasm; however, it would be necessary in the case of obvious or even suspected local infiltration.

In conclusion, the right ventricular myxoma is a rare anomaly and very few cases of this condition are reported 
in the literature. The presenting symptoms are syncope and right sided failure. Echocardiography is an ideal diagnostic modality. Surgical removal by the right atrial approach is sufficient in a small or an average size tumor but, the bicameral approach is advisable and preferable for a large tumor along with all the basic precautions to prevent an embolism and recurrence. Complete excision of the tumor with excision of the tissue surrounding the pedicle including endocardium and myocardium is sufficient.

\section{REFERENCES}

1. Gottsegen G, Wessely J, Arvay A, Temesvari A. Right ventricular myxoma simulating pulmonic stenosis. Circulation. 1963;27:95-7.

2. Crummy AB, Hipona FA. The radiographic aspects of right ventricular myxoma. Brit J Radiol. 1964;37:468-71.

3. Pontes JCDV, Silva GVR, Benfatti RA, Duarte JJ. Multiple left atrial myxoma: case report. Rev Bras Cir Cardiovasc. 2011;26(3):497-9

4. Melendez LJ, Sears GA, Coles JC. Right ventricular tumour demonstrated by echocardiography. Can Med Assoc J. 1978;118(1):62-3.

5. Bortolotti U, Mazzucco A, Valfré C, Valente M, Pennelli N, Gallucci V. Right ventricular myxoma: review of the literature and report of two patients. Ann Thorac Surg. 1982;33(3):277-84.
6. Kishimoto M, Sakaibori S. Primary tumor of the heart: report of a case with myxofibroma of the right ventricle. Am Heart J. 1959;57(5):769-74.

7. Hubbard TJ, Neil RN. Myxoma of the right ventricle. Report of a case with unusual findings. Am Heart J. 1971;81(4):548-53.

8. Liebler GA, Magovern GJ, Park SB, Cushing WJ, Begg FR, Joyner CR. Familial myxomas in four siblings. J Thorac Cardiovasc Surg. 1976;71(4):605-8.

9. Balk AH, Wagenaar SS, Bruschke AV. Bilateral cardiac myxomas and peripheral myxomas in a patient with recent myocardial infarction. Am J Cardiol. 1979;44(4):767-70.

10. Inoue L, Kobayashi K, Kato Y. A cardiac myxoma: case report of a massive right ventricular myxoma associated with a left atrial myxoma. Heart. 1971;2:1157.

11. Paraskevaidis IA, Triantafilou K, Karatzas D, Kremastinos DT. Right ventricular multiple myxomas obstructing right ventricular outflow tract. J Thorac Cardiovasc Surg. 2003;126(3):913-4.

12. van der Heusen FJ, Stratmann G, Russell IA. Right ventricular myxoma with partial right ventricular outflow tract obstruction. Anesth Analg. 2006;103(2):305-6.

13. Satitthummanid S, Tumkosit M, Benjacholamas V, Chattranukulchai P, Boonyaratavej S, Puwanant S. Right ventricular myxoma. J Am Coll Cardiol. 2011;57(5):630. 